\title{
Explore and Practice of Experiment Teaching Reform on the Principle and Application of Single Chip Microcomputer
}

\author{
Wu Haiyun, Wei Yong, Du Yanhong, Liu Yuan, Gao Jihui \\ Engineering College \\ Tianjin Agricultural University \\ Tianjin, China \\ haiyunwu2013@163.com
}

\begin{abstract}
Principle and Application of Single Chip Microcontroller (SCM) is a professional basic course for students majored in Measurement \& Control Technology and Instrument. It is also one of the specialized core courses for many majors. With the advent of internet, micro lecture has become a hot issue in research of education. The combination of the micro lecture with education, training, and various professional disciplines have become imperative. A brief overview of the problems presenting in the traditional experiment teaching of SCM was provided in this paper. And then the reform methods were explored. Proteus circuit simulation before experiment was introduced to improve the students' embedded system design ability. In order to effectively support experiment teaching, the traditional experiment resources were changed by several projects. In view of the key points and difficulties in the project, a knowledge map of experiment class was designed, and a micro lecture was made. In addition, the examination method has been reformed, in which the result-priority evaluation method has been changed into result-process evaluation combined method, so as to diversify course assessment and performance evaluation.
\end{abstract}

Keywords-internet; micro lecture; Principle and Application of SCM; Proteus

\section{INTRODUCTION}

As a member of embedded processor family, SCM has been widely used in intelligent instrument. Understanding and mastering the technology of SCM is a necessary skill for students majored in science and engineering. The Principle and Application of Single Chip is one of the specialized courses for students majored in the measurement technology and instrument, electrical automation engineering, electronic information engineering, and communication engineering etc., which is comprehensive and platform course with embodiment of the electronic technology, computer technology. It is set to strengthen students' application ability, after the student learned electrician, electronic technology, and $\mathrm{C}$ language course, etc. However, as the current higher requirement to the students on engineering practice ability, the original experiment content and teaching mode has been difficult to meet the requirements.

Proteus is a multi-functional EDA developed by Lab-center

Project of Teaching Quality and Teaching Reform of Undergraduate Education in Tianjin Ordinary Higher Education Institutions(171006101C); Innovation and Entrepreneurship Training Reform Model Projects of Tianjin Agricultural University (20170416, 20170813) in the UK, which provides a complete virtual laboratory for SCM teaching and application development. In addition, in today's internet + era, Wei-bo, We-chat, micro film has quietly walked into people's lives, and been changing people's work, study and life. Micro lectures have the characteristics of "short, small, pure and interesting". With the advent of the era of internet, the class has become a hot issue in research of education; the combination of the micro lecture with education, training, and various professional disciplines has become imperative. Aiming at the existing problem of single-chip computer experiment teaching, the Proteus simulation was joined in traditional teaching to establish an experiment simulation platform. Combined with the micro teaching, SCM experiment reform was explored. It was to great significance cultivate the students' study ability and ability to solve practical engineering problems.

\section{Traditional COURSES AND Micro LECTURES IN EXPERIMENTAL TEACHING}

Traditional single-chip computer experiment teaching was mainly taught by teachers, including parallel port, interruption, timer, and keyboard and display experiment. In the light of teaching practice in recent years, there were several problems in traditional experimental teaching. Firstly, the traditional experimental teaching was based on software development, which was not conducive to the development of students' system design ability. During the experiment, the students needed to master the principle and control method of the peripheral interface circuit, but there was no practical interface circuit design. Just as the teacher explained, students know how to control which pin, while they did not clear the circuit principle, and not clear the system design process. Students shall feel more difficult and even did not know how to start to design control system. Secondly, the traditional experiment teaching experiment was tense, which was not good for the students to fully understand the experimental content. Because of first-time learning micro-controller programming, they were not familiar with the programming language, the development environment, and no skills in experiment board. As a result, they could not to finish the experiment task within class. Even though students wanted to continue to do it outside of class, 
there was no experimental platform and they can't observe the results, which affected students' motivation. Thirdly, the traditional form of experimental teaching was not conducive to stimulating students' interest experiment teaching. Generally, an implementation was first put forward by teachers to explain the experimental circuit working principle and experimental requirements. And then students written and debug program of the experiment. Finally teachers checked students' results before the end of the experiment and score was also given. Such kind of experiments form was relatively boring that students tend to be interested in the first two experimental, while the interest was reduced then, especially during in difficult to experiment content, they shall be no motivation to overcome the difficulties.

Compared with traditional teaching, micro lectures showed great advantages in the form of teaching. Micro lectures imposed a micro video as the core, and to perform educational design to a certain knowledge point, so as to facilitate learners to anywhere at any time by smart phones, tablets and other mobile tools for online learning. With the characteristic of short, small, fine, micro lecture was first originated from 60 seconds course in 1993 by professor Iowa LeRoYA MeGrew of the University of North Lowa and one minute speech in 1995 by T. P. Kee of University of Napier, England. They were considered as the prototype of the micro lecture concept $[1,2]$. In 2008, the senior designers, teaching college online service manager David Penrose proposed micro lecture course in New Mexico, San Juan College. Then it was setting off a worldwide hot wave of micro lecture, in which "Khan Academy" in the United States was outstanding on the influence and high recognition. In recent years, the development of micro lecture has gradually attracted the attention of Chinese scholars[3-5].

\section{CURRICULUM REFORM PLAN}

In order to effectively solve the above problems and improve students' interest in experiment, the "single chip microcomputer principle and application design" experimental teaching was reformed as following: to increase the Proteus simulation circuit design from the teaching content, to realize the content of experiment item in the aspects of teaching mode, and to record project "micro lecture", at the same time, to reform the test method of experiment.

\section{A. The establishment of the Proteus circuit simulation and experimental platform}

With the introduction of Proteus simulation circuit design, students in the preparation stage of design circuit principle diagram of the experimental circuit has a profound thinking, saving micro-controller I/O pins. On the basis of the simulation circuit, the students write the program and finished the experiment by observing the simulation results from Proteus. In the experiment course, the students only needed to further debug the program on the experimental platform, observed the actual operation effect. In this case, the experiment efficiency was greatly improved.

At the same time, the design was based on the 51 SCM simulation platform. The relay, stepper motor, $8 * 8$ LED lattice screen and other peripherals were increase on the platform, on the basis of which to provide additional experiments to students with spare capacity. In addition, Proteus provided rich circuit components and instruments, students could also make secondary development on the simulation experiment platform, and it could be used to form embedded system with specific functions, so as to further develop the students' ability to solve practical engineering problems.

\section{B. The projectization of experimental content}

Project teaching method was derived from German professional education, and it was one of the effective measures for Germany to cultivate students in binary system. Its curriculum design process, from the typical tasks analysis its areas of action, to areas of action into learning areas, and then determine the learning environment design, to the teaching design process. The teaching design was based on the practical application, which students were the main body and lead by teacher. The teaching content system around the specific project was build up. Complex projects can also be divided into multiple specific tasks, with the participation of students and teachers in completing a specific project or task and launching [6]. In specific implementation process of teaching, the students' hands-on practice, learning to be a part in creating practice, not only at the end result, but the process of project or task was complete. In practice, students understand the knowledge and skills, developed the ability to analyze and solve problems [7]. Teaching content should conform to the development of students' cognitive regularity, from simple to complex gradually to improve the route of the complete arrangement of teaching content. And the single-chip computer related knowledge must be integrated into the various projects or tasks, so that the students to master relevant knowledge in study of microcomputer application at the same time. That was in order to achieve the purpose of the flexible application of single chip microcomputer technology.

Single-chip computer related knowledge included MCU internal structure, internal storage of distribution and application, single-chip microcomputer interrupt input output principle, the principle and application of timing counter, parallel extensions, serial port expansion, string line communication technology, single-chip microcomputer control, $\mathrm{A} / \mathrm{D}$ and $\mathrm{D} / \mathrm{A}$ conversion technology, etc. The project division should not only cover the related knowledge points of the single chip, but also the application and practical requirements of the single chip. Therefore, after analyzing electronic products based on MCU, the commonly used microcontroller and control devices were summed up, and were turned into various projects, which were shown in table 1.

It could be seen from table 1 that the single chip machine has been integrated into six items. The first project was based partly on learning and practice to lay the foundation for followon projects; the latter five projects increased the complexity of the project and project in order to improve the application program. It would be better motivate the enthusiasm of students in the process of concrete practice through the Proteus for circuit design and Keil of program design and the software and hardware alignment. With assessment of classroom practice at the same time, students would not only acquire the 
ability to acquire knowledge and apply knowledge, but also improve the comprehensive ability of analyzing the problem of reconciliation.

TABLE I. PROJECT OF EXPERIMENT

\begin{tabular}{|c|c|c|}
\hline Number & Name of Project & Task \\
\hline 1 & Minimum system of SCM & Design micro controller minimum system circuit controls the light-emitting diode flashing \\
\hline 2 & Simple traffic light design & $\begin{array}{l}\text { Task 1: single chip computer controlled water lamp design } \\
\text { Task 2:60 seconds timer design } \\
\text { Task 3: simple traffic light design }\end{array}$ \\
\hline 4 & Simple frequency meter design & $\begin{array}{l}\text { Task 1: static display hardware and software design } \\
\text { Task 2: dynamic display of hardware and software design } \\
\text { Task 3: simple frequency meter design }\end{array}$ \\
\hline 5 & Simple digital voltmeter design & $\begin{array}{l}\text { Task 1: simple waveform generator design } \\
\text { Task 2: simple digital voltmeter design }\end{array}$ \\
\hline 6 & Remote detector design & $\begin{array}{l}\text { Task 1: single chip computer and computer communication software and hardware design } \\
\text { Task 2: temperature and humidity remote detector design }\end{array}$ \\
\hline
\end{tabular}

\section{Recording "Micro Lecture"}

In the teaching process, according to the experiment content, knowledge map of single chip microcomputer principle and application was designed for experimental courses. The relevant knowledge necessary was showed during the experimental process through the knowledge map. And through the hyperlinks form associated with the knowledge of the learning resources, the knowledge map was used to assist students make full use of the functions of knowledge management, thus to complete the experiment content.

It was difficult for experiment due to scheduling. In order to support the student to complete the experiment content better, the micro lecture was recorded aiming at key points and difficulties in the design process, complementary knowledge and Proteus simulation tools. Through the video interpretation form, students would familiar with the simulation platform faster, and overcome the difficulties in the process of design better. "Class" in video form mainly course ware or simulation tools demonstration operation, try to play a role of animation and Flash course ware, add interest, which would attracted students active learning.

\section{Experiment test reform}

As a course which emphasis on practical ability, it should adopt diversified way of performance evaluation. It would not only examine the theoretical knowledge, but also examines the whole process of course. It could avoid the students in the study of natural rote learning, cope with the phenomenon of the final exam, so that to achieve "combined process was given priority to with the results of evaluation to the" way of evaluation. A variety of tests were designed, such as a "structured scoring" approach. Ratings of so-called "structured" refers to the course grade students, such as multiple aspects, including "at ordinary times (to the class, homework, class participation), experiment (access, process, and report to the test, test, quizzes, a midterm and final exam) and propagation (integrated operation, the healthy birth body, project design)", etc. The test method for most of students were as following: circuit design achievement (30\%), program design achievement $(60 \%)$, and additional experiment result $(10 \%)$.

(a) Circuit design achievement:(30\%): circuit design was completed in extracurricular experiment circuit design, as each experiment preview link. Students need to record the screen simulation circuit, and complete the review report.

(b) Program design achievement (60\%): program design was mainly inspects the student experiment program completion. The achievement was according to the experimental platform demonstration effect, application on condition and completion of the speed, code quality, and experiment reports from several aspects such as the inspection.

(c) Additional experiment result (10\%): each additional experiment content was arrangement to each experiment. After students completed the program, and simulated on Proteus platform, teachers according to the situation of students completed made the scene to points, so that fully mobilize students' experiment by additional experiments.

Basis on varieties of learning ability in the process of teaching, students with good basic academic capacity and interest in the design of microcomputer system, can independent design and complete a microcomputer system instead of course the final exam. The inquiry learning and project implementation of the entire process instead of two hours of eugenics exams at the end of body, can give full play to the excellent students' potential and creativity, reflect the student as the main body and their aptitude education concept.

\section{ACHIEVEMENT OF THE CURRICULUM EXPERIMENT REFORM}

After two semesters of practice, the reform of the curriculum experiment has achieved good results. By introducing the design link of the Proteus simulation circuit, the students generally reflected the design understanding of the SCM system, and the process design thinking was clearer. In addition, through the knowledge map, the "class" and so on the construction of teaching resources, to play a better role to support the students' practical single-chip system design, the experimental effect was rising steadily. Experimental curriculum reform also improves the students' learning interest, and interest in pushing consciousness.

\section{CONCLUSIONS}

In experiment teaching of "single chip microcomputer principle and application design", the introduction of Proteus 
circuit design and simulation of link, can effectively exercise the students' ability of embedded system design, make up for the shortage problem of experimental classes, and save the laboratory hardware investment. But in the process of implementation, in addition, for better motivation to study, we should make full use of the achievement lever in the teaching, and guide the students in diversity.

\section{ACKNOWLEDGMENT}

This research was funded by the Project of Teaching Quality and Teaching Reform of Undergraduate Education in Tianjin Ordinary Higher Education Institutions (171006101C); and the Innovation and Entrepreneurship Training Reform Model Projects of Tianjin Agricultural University (20170416, 20170813).

\section{REFERENCES}

[1] T. S. Hu, M. Y. Huang, M. Li, "Three stages of China's micro curriculum development and its implications". Remote education magazine, vol. 4. Pp. 36-42, 2013. (In Chinese)

[2] Y. C. Guo, "Microlectures on the present situation, problem and future of microlectures, Digital education, vol. 1, pp. 1-8, 2016. (In Chinese)

[3] Z. H. Feng, X. D. Zheng, “New definition: from technical development to effective design", Digital education, vol. 4, pp. 56-61, 2015.(In Chinese)

[4] X. J. Liu, J. P. Zhang, W. F. Du, "Based on the five teaching principle of micro teaching design research", Journal of modern distance education research, vol. 1, pp. 82-89+97, 2015. (In Chinese)

[5] S. C. Zhong, Z. Zhang, Y. W. Tang, "The key question of design and application of microcourses, China electrochemical education, vol. 4, pp. 85-88, 2014. (In Chinese)

[6] T. Y. Jang, "The philosophy of the education curriculum development", Journal of vocational college in tianjin, vol. 1, pp. 3-6, 2010. (In Chinese)

[7] Y. J. Zhang, Y. D. Li, X. W. Wang, "Project teaching method in the single-chip computer courses teaching practice", Journal of Chinese modern education equipment, vol. 3, pp. 65-66, 2014. (In Chinese) 